\title{
The role of GDF15 in bone metastasis of lung adenocarcinoma cells
}

\author{
LIAN DUAN $^{1 *}$, HAI-LIN PANG $^{1}{ }^{*}$, WEN-JUN CHEN $^{1}$, WEI-WEI SHEN $^{1}$, PEI-PEI CAO ${ }^{1}$, \\ SHU-MEI WANG ${ }^{2}$, LI-LI LIU ${ }^{1}$ and HE-LONG ZHANG ${ }^{1}$ \\ Departments of ${ }^{1}$ Oncology and ${ }^{2}$ Pathology, Tangdu Hospital, The Air Force Medical University, \\ Xi'an, Shaanxi 710038, P.R. China
}

Received July 30, 2018; Accepted February 15, 2019

DOI: $10.3892 / o r .2019 .7024$

\begin{abstract}
Lung cancer is the most common malignant tumor in China. It often metastasizes to bone, thereby significantly shortening the lives of patients, and reducing their quality of life. However, the efficacy of treatment for bone metastasis of lung cancer at this stage is very limited. The development and clinical application of molecular-targeted drugs for the effective targeted therapy of bone metastasis of lung cancer are urgently required. The growth differentiation factor 15 (GDF15) gene which may be associated with bone metastasis of lung cancer, was screened out by whole-genome sequencing. In the present study, we used a recombinant GDF15 lentivirus technique to upregulate the expression of GDF15 in lung adenocarcinoma A549 cells, and the results revealed that GDF15 could inhibit the proliferation, migration and invasion, while promoting apoptosis of A549 cells. In addition, GDF15 significantly decreased the number and sites of lung metastases and bone metastases in vivo compared to the control group. Finally, it was revealed that Smad2 and phospho-Smad2 protein expression was lower in the GDF15-overexpressing A549 cells. This result indicated that the tumor suppressive effect of GDF15 may be related to the TGF- $\beta /$ Smad signaling pathway, although more studies are still required for confirmation. In summary, GDF15 inhibited the growth and bone metastasis of lung adenocarcinoma A549 cells, and this effect may be achieved through the TGF- $\beta /$ Smad signaling pathway.
\end{abstract}

Correspondence to: Professor Li-Li Liu or Professor He-Long Zhang, Department of Oncology, Tangdu Hospital, The Air Force Medical University, 569 Xinsi Road, Xi'an, Shaanxi 710038, P.R. China E-mail: lily123fmmu@163.com

E-mail: cnxazhl@163.com

${ }^{*}$ Contributed equally

Key words: GDF15, lung adenocarcinoma, bone metastasis

\section{Introduction}

The incidence and mortality rate of lung cancer is ranked first in malignant tumors in China (1). Adenocarcinoma is the most common pathological type of lung cancer, accounting for approximately $1 / 3$ of all lung cancers, and is still on the rise. Due to the poor anticancer awareness of Chinese people, more than $60 \%$ of patients have already dominant or recessive metastases when they are diagnosed (2). Bone is a common metastatic site of lung adenocarcinoma, with an incidence of approximately $35 \%$ (3). The associated skeletal-related events (SREs) such as pathological fractures, bone pain, spinal cord compression and hypercalcemia severely reduce the quality of life in patients (4). In recent years, the use of bisphosphonate has delayed the destruction of bone to some extent (5), but the overall therapeutic effect is not ideal due to its inability to promote new bone formation, the limited therapeutic effects and the serious side-effects (6). Therefore, searching for target genes related to bone metastasis of lung cancer and exploring their mechanism can lay a theoretical foundation for the treatment of bone metastasis of lung cancer.

Our group has long been committed to the study of the mechanism of lung cancer bone metastasis, and several related molecules have been found (7-14). We performed whole-genome sequencing on two groups of lung adenocarcinoma patients (with bone metastasis or without bone metastasis) in a previous study (unpublished data), and of the 240 differential genes that were found between the two groups, the GDF15 gene was one of the differential genes. However, there have been no studies on whether the GDF15 gene is related to bone metastasis in lung adenocarcinoma. Thus, we carried out this experiment in order to clarify the role and mechanism of GDF15 in bone metastasis of lung adenocarcinoma.

\section{Materials and methods}

Cell culture and invasive selection. The human lung adenocarcinoma A549 cells were purchased from the American Type Culture Collection (ATCC; Manassas, VA, USA) and were maintained in liquid nitrogen at our laboratory (Department of Oncology, Tangdu Hospital, Xi'an China). The highly invasive A549 cells used in this experiment were systematically selected by multiple invasion process as previously reported 
for greater migration and metastasis capacity (15). The culture medium was prepared with RPMI-1640 medium (Gibco; Thermo Fisher Scientific, Inc., Waltham, MA, USA) and 10\% fetal bovine serum (FBS; Biochrom GmbH, Berlin, Germany), A549 cells were maintained in this media at $37^{\circ} \mathrm{C}$ with $5 \%$ $\mathrm{CO}_{2}, 100 \mathrm{U} / \mathrm{ml}$ streptomycin and $100 \mathrm{U} / \mathrm{ml}$ penicillin.

Cells stable transfection. Recombinant GDF15 lentivirus (homo; NM_004864.2), NC lentivirus (Ubi-MCS-3FLAGSV40-EGFP-IRES-puromycin) and Luciferin-LV (Ubi-MCS-Luc-IRES-Puromycin) were synthesized by Shanghai GeneChem Co., Ltd. (Shanghai, China), with virus titers of $1 \times 10^{9}, 2 \times 10^{9}$ and $5 \times 10^{8} \mathrm{TU} / \mathrm{ml}$. The GDF15-LV and NC-LV viruses were respectively added into target A549 cells at a multiplicity of infection (MOI) of 20 with ENi.S and $1 \mu \mathrm{g} / \mathrm{ml}$ Polybrene (Shanghai GeneChem Co., Ltd.). The infected A549 cells were selected for 2 weeks using a medium with a concentration of $1.0 \mu \mathrm{g} / \mathrm{ml}$ puromycin to obtain stably transfected LV-GDF15-A549 and LV-NC-A549 cells. Then the puromycin level in the culture medium was maintained at $0.5 \mu \mathrm{g} / \mathrm{ml}$. Luciferin-LV virus was used to view the distribution of tumor cells in vivo, it was used to infect both LV-GDF15-A549 and LV-NC-A549 cells by the same method. The interference efficacy was assessed by real-time PCR and western blot analysis.

$R T-q P C R$. Total RNA was isolated from the cells using TRIzol reagent (Thermo Fisher Scientific, Inc.) and purified by chloroform and isopropanol. After washing with absolute ethanol, the RNA was dissolved in deionized water and $2 \mu \mathrm{l}$ were used for purity and concentration determination. RNA was reverse-transcribed into cDNA using QuantiNova ${ }^{\mathrm{TM}}$ Reverse Transcription kit (Qiagen GmbH, Hilden, Germany). qPCR was performed using QuantiNova ${ }^{\mathrm{TM}}$ SYBR-Green PCR kit (Qiagen $\mathrm{GmbH}$ ) and the thermocycling conditions are listed in Table I. GAPDH was used as an endogenous control in the present study and the primer sequences are listed in Table II. Real-time fluorescence signals were detected by Mx3005P qPCR System (Agilent Technologies, Inc., Santa Clara, CA, USA), and the gene expression was quantified using the $2^{-\Delta \Delta C q}$ method (16).

Western blot analysis. The A549 cells were lysed by RIPA buffer (Beyotime Institute of Biotechnology, Shanghai, China), and the protein was extracted and then quantified with a BCA protein assay kit (Thermo Fisher Scientific, Inc.). Total protein $(15 \mu \mathrm{g})$ from each sample was loaded on 12\% SDS-PAGE and transferred to a nitrocellulose membrane. The non-specific protein on the membrane was blocked slowly at $37^{\circ} \mathrm{C}$ for $1 \mathrm{~h}$ using 5\% fat-free milk. Then, the membrane was incubated with rabbit anti-human GDF15 polyclonal antibody (dilution 1:1,000; cat. no. EPR19939; Abcam, Cambridge, UK) or mouse monoclonal antibody against $\mathrm{Smad} 2$ (dilution 1:1,000; cat. no. sc-101153; Santa Cruz Biotechnology, Santa Cruz, CA, USA) or rabbit monoclonal antibody against phospho-Smad2 (dilution 1:1,000; cat.no. sc-135644; Santa Cruz Biotechnology) at $4{ }^{\circ} \mathrm{C}$ overnight. Mouse anti- $\beta$-actin polyclonal antibody was used as the internal control (dilution 1:1,000; cat. no. GTX83163; GeneTex, Inc., Irvine, CA, USA). Subsequently, the membrane was incubated with secondary antibody-HRP-conjugated goat
Table I. RT-PCR thermocycling conditions.

\begin{tabular}{lcr}
\hline Step & Temperature $\left({ }^{\circ} \mathrm{C}\right)$ & Time \\
\hline Step 1 & 95 & $2 \mathrm{~min}$ \\
Step 2 & 95 & $10 \mathrm{sec}$ \\
& 60 & $30 \mathrm{sec}$ \\
& Number of cycles, 40 & \\
\hline
\end{tabular}

anti-rabbit IgG (dilution 1:3,000; cat. no. ZB-2301; ZhongShan Jinqiao, Beijing, China) or HRP-conjugated goat anti-mouse IgG (dilution 1:1,000; cat. no. SAB3701073; Sigma-Aldrich; Merck KGaA, Darmstadt, Germany) at $37^{\circ} \mathrm{C}$ for $1 \mathrm{~h}$. Finally, the target proteins were visualized by chemiluminescence (Pierce Biotechnology, Inc.; Thermo Fisher Scientific, Inc.) and AlphaImager 2200 software v3.2.1.2 (Alpha Innotech Corp.; ProteinSimple, San Jose, CA, USA) was used to analyze the densitometry of bands.

MTT assay. Single cell suspensions were prepared and seeded into 96 -well plates at $2 \times 10^{3}$ cells/well, and each well contained $200 \mu$ l RPMI-1640 medium with 10\% FBS. A total of eight 96-well plates were inoculated and placed back into the carbon dioxide cell incubator. One of the eight plates was selected at a fixed daily time and $20 \mu \mathrm{l} /$ well of MTT stock solution was added $(5 \mathrm{mg} / \mathrm{ml})$. The plate was then incubated at $37^{\circ} \mathrm{C}$ for $4 \mathrm{~h}$, and the medium was removed and $150 \mu \mathrm{l}$ of dimethyl sulfoxide (DMSO) was added. After sufficient shaking, the absorbance was detected at $580 \mathrm{~nm}$ by a microplate reader (Multiskan MK3; Thermo Fisher Scientific, Inc.). This assay was performed in triplicate.

Colony formation assay. The cells in logarithmic growth phase were seeded into 6-well plates at 200 cells/well, supplemented with complete medium to $2 \mathrm{ml}$, and then the cells and the medium were mixed by shaking the 6 -well plates slowly. The 6-well plates were incubated at $37^{\circ} \mathrm{C}$, with $5 \% \mathrm{CO}_{2}$ for two weeks. The cells were subsequently stained with $0.25 \%$ crystal violet, and colonies of $>50$ cells were counted. This assay was duplicated in triplicate.

Cell migration and invasion assay. The serum of the culture medium was removed $12 \mathrm{~h}$ before the experiment, and the invading potential of the cells was investigated by $8-\mu \mathrm{m}$ pore size Transwell inserts (Corning Inc., Corning, NY, USA). The cells were resuspended in serum-free RPMI-1640 medium and the concentration was adjusted to $1 \times 10^{4} / \mathrm{ml}$. Then $200 \mu \mathrm{l}$ of cell suspension was placed into the upper chamber of the wells, and $500 \mu \mathrm{l}$ RPMI-1640 medium with $10 \%$ FBS was placed in the bottom chamber. After $24 \mathrm{~h}$ of incubation at $37^{\circ} \mathrm{C}$, the chamber was removed, rinsed with PBS, and the cells on the upper surface of the membrane filters were removed with a cotton swab. The remaining cells on the lower surface were fixed in $95 \%$ ethyl alcohol for $5 \mathrm{~min}$, and then were stained with $0.5 \%$ crystal violet for $10 \mathrm{~min}$. Ten fields were selected randomly and the invasive cells were counted manually. All assays were performed three times. 
Table II. Primers used in quantitative polymerase chain reaction analysis.

\begin{tabular}{lcc}
\hline Gene & Forward primer (5'-3') & Reverse primer (5'-3') \\
\hline GDF15 & CAGATGCTCCTGGTGTTGCT & CTGGAGTCTTCGGAGTGCAA \\
GAPDH & GAAGGTGAAGGTCGGAGTC & GAAGATGGTGATGGGATTTC \\
\hline
\end{tabular}

The cell invasion assays followed the same protocol as aforementioned except for the 70- $\mu 1$ Matrigel (dilution 1:8; Corning Inc., Corning, NY, USA) that was used to pre-coat the upper chamber of the wells.

Flow cytometry. The cell apoptosis rate was assessed by flow cytometry with an Annexin V-FITC/PI kit (Nanjing KeyGen Biotech Co., Ltd., Nanjing, China). Cells were harvested by centrifugation at $800 \mathrm{x}$ g for $10 \mathrm{~min}$, and washed twice with $2 \mathrm{ml}$ ice-cold Dulbecco's phosphate-buffered saline (DPBS). Then, the cells were resuspended in $300 \mu \mathrm{l} 1 \mathrm{X}$ binding buffer at a concentration of $5 \times 10^{5}$ cells $/ \mathrm{ml}$. Subsequently, Annexin V-FITC $(10 \mu \mathrm{l})$ and PI $(10 \mu \mathrm{l})$ were added successively and the tube was incubated at $4{ }^{\circ} \mathrm{C}$ for $30 \mathrm{~min}$ in the dark. The cells were washed with ice-cold DPBS again. The apoptotic level was analyzed using a FACSCalibur system (BD Biosciences, Franklin Lakes, NJ, USA) and the sum of the upper right and lower right quadrants was the ratio of apoptosis.

In vivo metastasis experiment. Twenty four-week old NOD-SCID female mice weighing 20-25 g, were purchased from Hunan SJA Laboratory Animal Co., Ltd. (Changsha, China). They were housed in a specific pathogen-free (SPF) laboratory animal environment (temperature, $22^{\circ} \mathrm{C}$; ventilation rate, $15 / \mathrm{h}$; light/dark cycle, $12 / 12 \mathrm{~h}$; food was sterilized with Cobalt-60 irradiation and water was autoclaved, and access to the food was ad libitum; tumor size not exceed $2.0 \mathrm{~cm}$ ) by professional breeders and were divided into the experimental and the control group both with an equal number of mice. A549-GDF15 and A549-NC cells in the logarithmic growth phase were harvested with DPBS to a cell suspension with a concentration of $3 \times 10^{7}$ cells $/ \mathrm{ml}$. Furthermore, the cell viability was determined with trypan blue exclusion test and the result was $>90 \%$. Then, the cells were slowly injected into each mouse with $200 \mu \mathrm{l}$ cells in DPBS via the tail vein.

When the experimental mice began to develop symptoms such as lameness, joint stiffness, decreased exercise capacity, paraplegia, or the experiment reached 42 days, the experiment was immediately terminated. The mice were anesthetized with chloral hydrate $(400 \mathrm{mg} / \mathrm{kg})$ by intraperitoneal injection and $150 \mu \mathrm{l}$ D-Luciferin solution $(20 \mathrm{mg} / \mathrm{ml})$ was injected into each mouse by the tail vein way. Five minutes later, the In Vivo Imaging System (Carestream Health Canada, Concord, ON, Canada) was used to obtain X-ray images and biofluorescence imaging of the mice in order to evaluate the bone metastasis. Finally, the mice were sacrificed humanely in a transparent euthanasia device (ventilated isoflurane for $1 \mathrm{~min}$ before the mice were laid, and constant ventilated isoflurane for another $3 \mathrm{~min}$ after the mice expired). Afterwards, the lungs were excised and weighed, and the number of metastatic lesions $>0.5 \mathrm{~mm}$ in diameter on the surface of the lungs was counted.

Statistical analysis. The Student's t-test was used to analyze the statistical difference between the A549-GDF15 group and the A549-NC group in cell proliferation, colony formation, migration, invasion, apoptosis rate assay and metastasis analysis in vivo, and the statistical SPSS 19 software package (IBM Corp., Armonk, NY, USA) was utilized. P<0.05 was considered to indicate a statistically significant difference.

\section{Results}

The expression levels of GDF15 are effectively increased in transfected cells. The successful construction of A549 cells with high expression of GDF15 was confirmed by RT-PCR (Fig. 1A) and western blot analysis (Fig. 1B) from mRNA and protein levels, respectively. Furthermore, the EGFP gene was transfected with the lentivirus vector as a positive control to reveal the transfection efficacy. The results revealed that $>85 \%$ of cells were EGFP-positive $24 \mathrm{~h}$ after transfection (Fig. 1C).

Overexpression of GDF15 inhibits the proliferation ability of A549 cells. The changes on cell proliferation were evaluated by MTT and colony formation assays. As revealed in the cell growth curve in Fig. 2A, the slope of the ' $S$ ' curve of the A549-GDF15 group was smaller. A two-sample t-test was performed on the OD values of the two groups on the 3rd, 4th and 5th day, and the results revealed that the A549-GDF15 group was lower than the A549-NC group $(\mathrm{P}<0.05)$. Consistently, the colony formation rate of A549-GDF15 cells $(0.170 \pm 0.018)$ in the experimental group was significantly lower than that of the control group $(0.442 \pm 0.059)$, and the difference was statistically significant $(\mathrm{P}<0.01)$ (Fig. 2C). Moreover, the colonies that formed in the experimental group were significantly smaller than the control group (Fig. 2B). In conclusion, these results indicated that GDF15 inhibited the proliferation of A549 cells.

A high level of GDF15 inhibits migration and invasion in A549 cells. The number of A549-NC and A549-GDF15 cells that passed through the membrane filters without Matrigel were $175 \pm 16.84$ and $54 \pm 6.11$, respectively (Fig. 3A and B). In addition, the number of the cells that passed through the membrane filters with Matrigel were $77 \pm 9.08$ and $23 \pm 3.95$, respectively (Fig. 3C and D). These results revealed that upregulation of GDF15 in A549 cells significantly decreased the invasive and migratory abilities of A549 cells $(\mathrm{P}<0.01)$.

Upregulation of GDF15 promotes apoptosis of A549 cells. Cell apoptosis was detected by Annexin V-FITC/PI double staining 
A
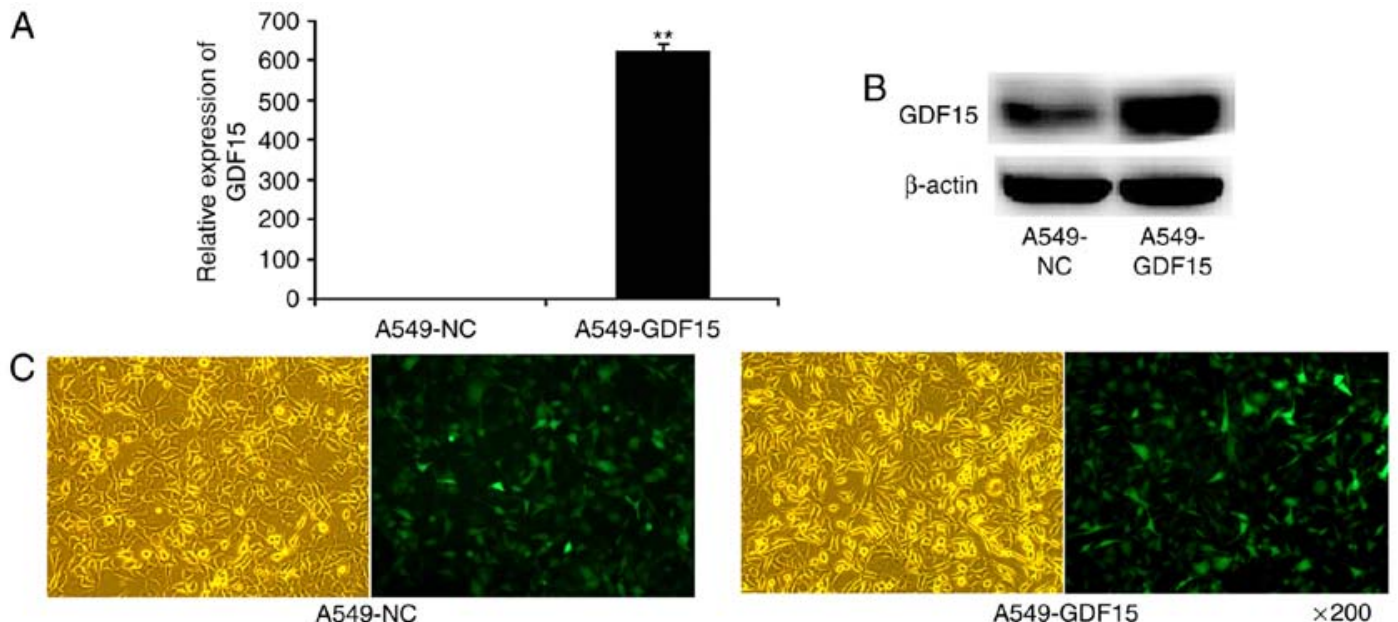

Figure 1. A549 cells with a high level of GDF15 successfully constructed. (A) mRNA levels of GDF15 were assessed by reverse transcription-quantitative polymerase chain reaction $\left({ }^{* *} \mathrm{P}<0.01\right)$. (B) Protein expression levels were assessed by western blot analysis $(\mathrm{C})$. Infection efficiency of GDF15 siRNA was observed by fluorescence microscope. GDF15, growth differentiation factor.

A

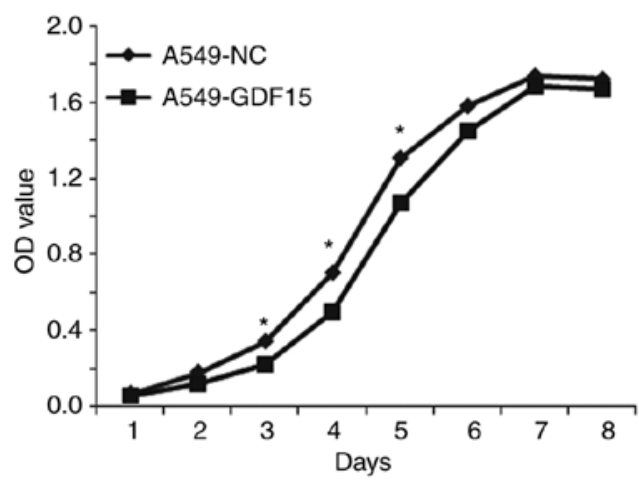

B
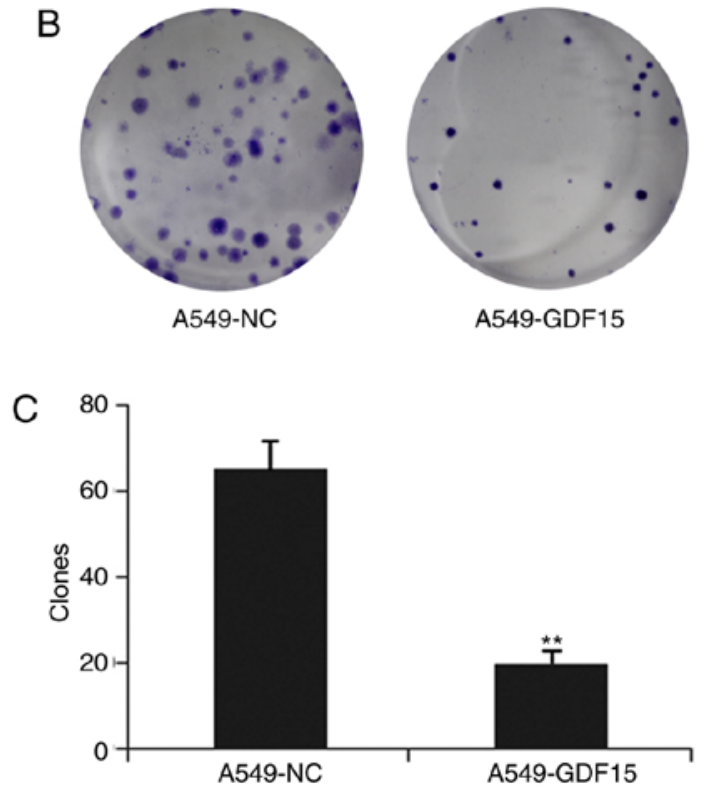

Figure 2. Effect of GDF15 on the proliferation and colony formation of A549 cells. (A) Cell proliferation curve by MTT assay ("P<0.05). (B) Images of A549-NC and A549-GDF15 cell colony formation. (C) Statistical analysis of the colony formation assay ("* $\mathrm{P}<0.01)$. GDF15, growth differentiation factor.

kit. The apoptosis rates of A549-NC and A549-GDF15 were $17.19 \pm 2.14$ and $25.14 \pm 2.66 \%$ by three independent experiments, and the difference of the two groups was statistically significant $(\mathrm{P}<0.05)$ which meant that GDF15 increased the apoptosis of A549 cells (Fig. 4).

GDF15 suppresses bone metastasis of A549 cells in vivo. In order to analyze the biological role of GDF15 in lung cancer cell bone metastasis in vivo, bone metastasis or no bone metastasis was detected using a mouse model, and the rate of bone metastasis between the A549-NC group and the A549-GDF15 group was compared. If a mouse was identified with bone metastasis, the total number of bone metastasis lesions was counted and analyzed with the Student's t-test. When bone metastasis symptoms appeared or after six weeks of experimentation, the mice were anesthetized and the bone metastases were investigated using X-ray imaging and luciferase imaging,
Table III. Incidence of bone metastasis and the number of metastasis lesions formed in NOD-SCID mice.

\begin{tabular}{lcc}
\hline Cells & Incidence & Numbers of bone metastases \\
\hline A549-NC & $7 / 10$ & $1.60 \pm 1.35$ \\
A549-GDF15 & $1 / 10$ & $0.10 \pm 0.32^{\mathrm{a}}$ \\
\hline
\end{tabular}

The incidence of metastases in mice and the number of metastatic lesions in bone at the 6th week after inoculation. Values are presented as the means $\pm \mathrm{SD} .{ }^{\mathrm{a}} \mathrm{P}=0.007$ compared with the control group.

and the data was evaluated by two experienced investigators. As presented in Table III, 7 out of 10 recipient mice developed bone metastasis in the A549-NC group at day 42 compared 


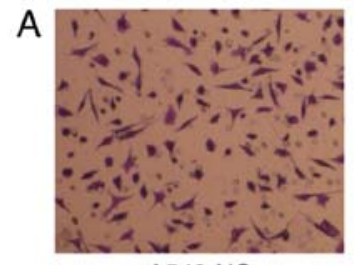

A549-NC

B

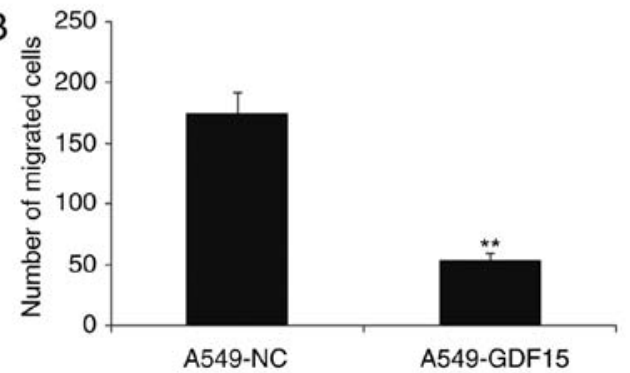

C

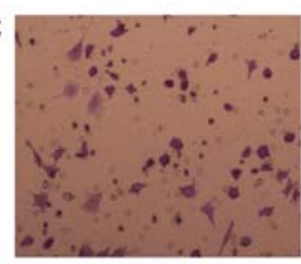

A549-NC

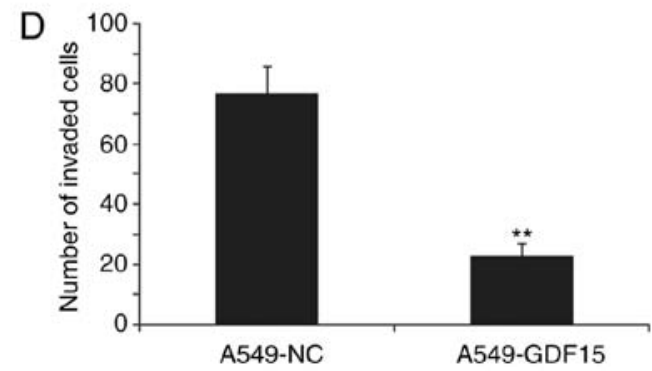

Figure 3. Migration and invasion capabilities of A549-GDF15 and A549-NC cells. (A) Representative images of the stained migrated cells. (B) Quantification of the results from the cell migration assay $\left({ }^{* *} \mathrm{P}<0.01\right)$. (C) Representative images of the stained invaded cells. (D) Quantification of the results from the cell invasion assay $\left({ }^{* *} \mathrm{P}<0.01\right)$. Data are expressed as the mean \pm standard deviation. GDF15, growth differentiation factor.
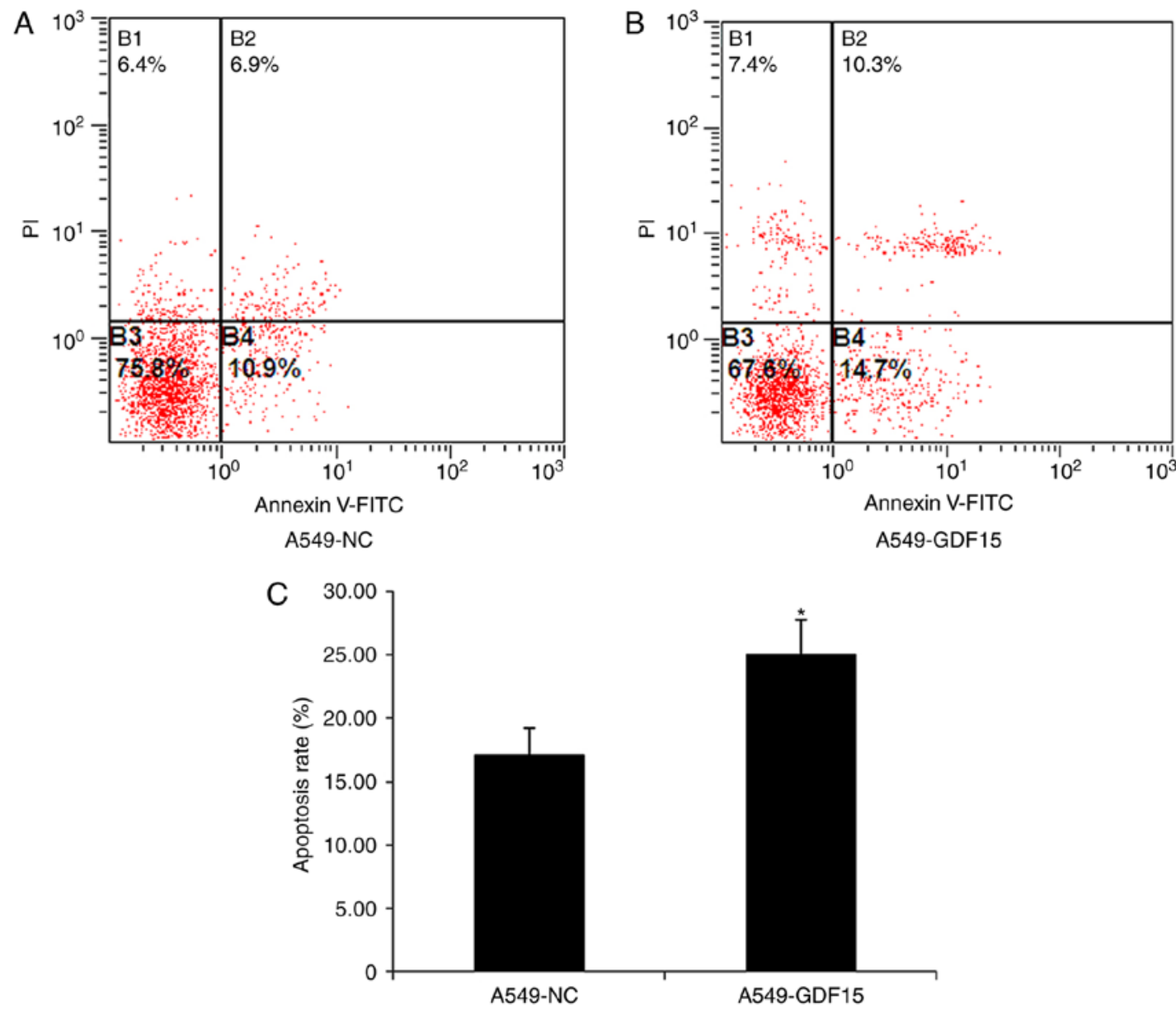

Figure 4. Cell apoptosis was detected by FACSCalibur system with an Annexin V-FITC/PI kit. (A and B) The images of the apoptosis rate of A549-NC and A549-GDF15 cells. (C) Statistical analysis of the apoptosis rate $\left({ }^{*} \mathrm{P}<0.05\right)$. GDF15, growth differentiation factor.

with 1 out of 10 mice in the A549-GDF15 group. Moreover, the total number of bone metastasis lesions was counted, and the results revealed a statistical difference in the number of bone metastases in the two groups $(\mathrm{P}<0.01)$, which suggested that GDF15 could markedly inhibit osteolytic bone metastasis lesions. Representative X-ray images of skeletal metastasis are presented in Fig. 5, and D-Luciferin biofluorescence signals were detected in the corresponding positions (Fig. 6). 
Table IV. Number of lung tumors and weight of the lungs.

\begin{tabular}{|c|c|c|c|c|c|c|c|c|c|c|}
\hline No. & 1 & 2 & 3 & 4 & 5 & 6 & 7 & 8 & 9 & 10 \\
\hline \multicolumn{11}{|l|}{$\mathrm{NC}$ group } \\
\hline No. of tumors & 1 & 0 & 2 & 4 & 2 & 0 & 8 & 1 & 2 & 2 \\
\hline Weight of the lungs (g) & 0.19 & 0.13 & 0.14 & 0.14 & 0.11 & 0.11 & 0.26 & 0.12 & 0.17 & 0.12 \\
\hline \multicolumn{11}{|l|}{ GDF15 group } \\
\hline Number of tumors & 0 & 0 & 0 & 0 & 0 & 1 & 0 & 0 & & \\
\hline Weight of the lungs (g) & 0.12 & 0.12 & 0.10 & 0.13 & 0.11 & 0.10 & 0.11 & 0.11 & & \\
\hline
\end{tabular}
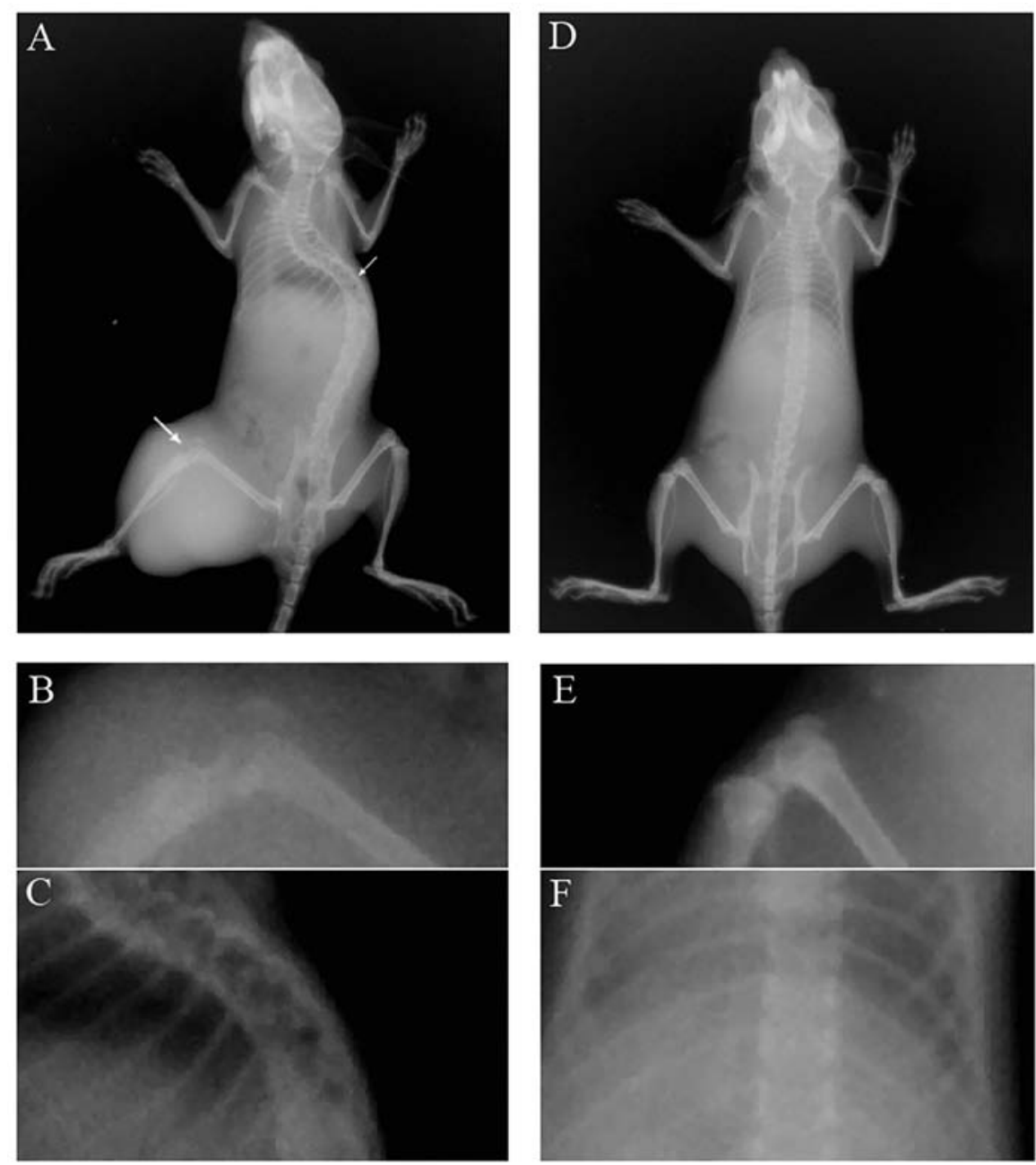

A549-NC

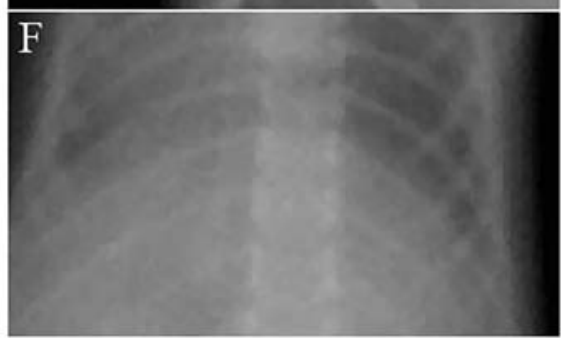

A549-GDF15

Figure 5. (A) Representative X-ray image of a mouse in the A549-NC group. (B and C) Osteolytic bone metastasis lesions in the knee joint and spines of the mouse in A. (D) Representative X-ray image of a mouse in the A549-GDF15 group. (E and F) Normal knee joint and spine. GDF15, growth differentiation factor.

GDF15 still inhibits tumor growth in vivo. The NOD-SCID mice were sacrificed by excessive anesthesia as aforementioned. After dissection, the lungs were weighed and the number of tumors with a diameter $>0.5 \mathrm{~cm}$ on the lung surface was counted. A part of the results is presented in Table IV and Fig. 7. The statistical analysis revealed that the weight of the lungs of A549-GDF15 mice was lighter $(\mathrm{P}<0.05)$ and the number of tumors was less $(\mathrm{P}<0.05)$ than the control group. Overexpression of GDF15 could lower the tumor burden in vivo. Thus, these results revealed that reduction of bone metastasis may be directly related to the lower number of tumors in the NOD-SCID mice with A549 cells overexpressing GDF15.

The inhibitory effects of GDF15 on lung adenocarcinoma cell line A549 may involve the TGF- $\beta /$ Smad signaling pathway. In order to explore the mechanism of GDF15 inhibition of the growth and bone metastasis of A549 cells, we used western blot analysis to detect the different expression of proteins in A549-NC and A549-GDF15 cells. The results revealed that the 


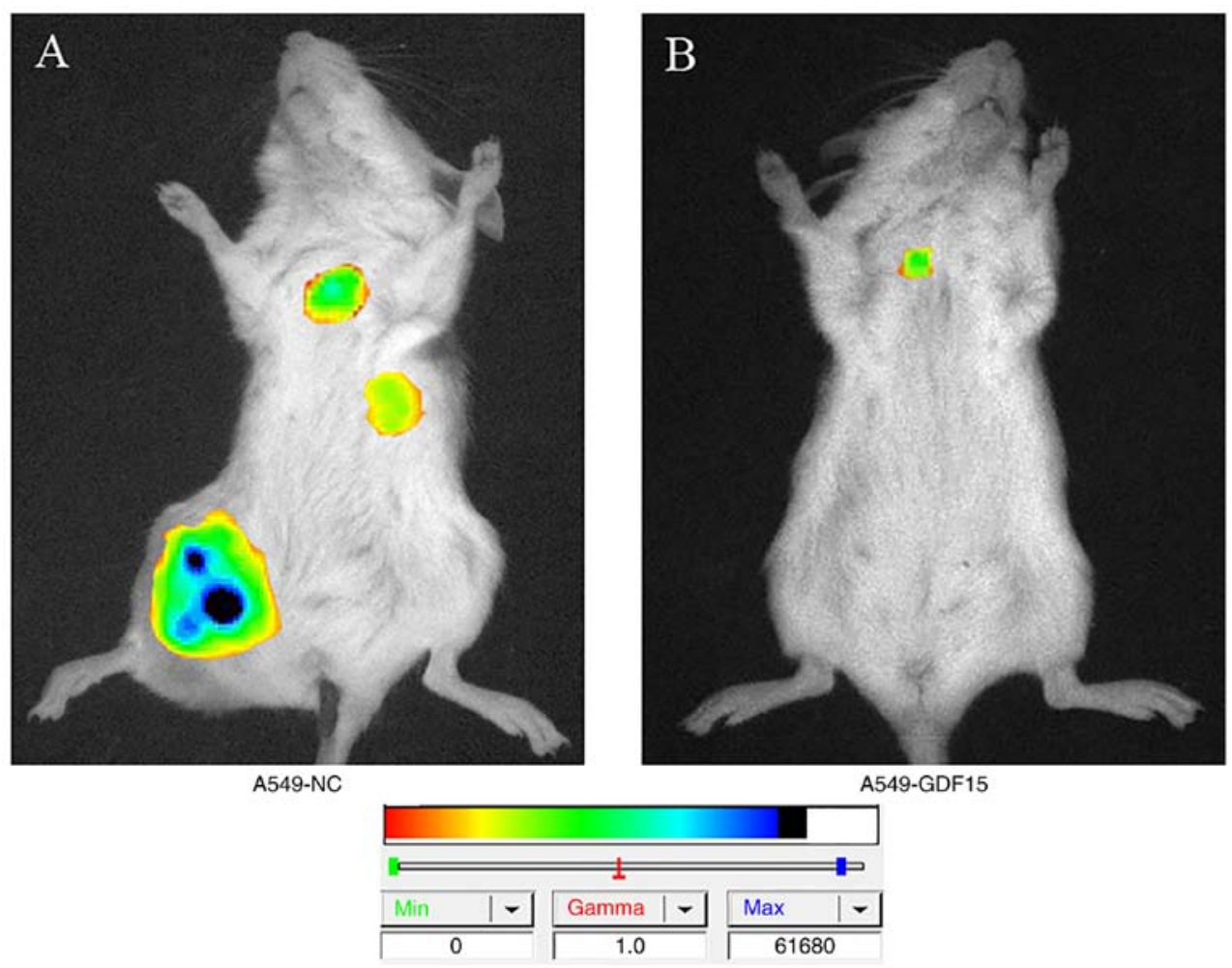

Figure 6. D-Luciferin biofluorescence in NOD-SCID mice. (A) Tumor growth was assessed by in vivo luciferase imaging at the corresponding localization of the mouse in Fig. 5A. (B) The mouse in Fig. 5D was assessed by in vivo luciferase imaging.

A
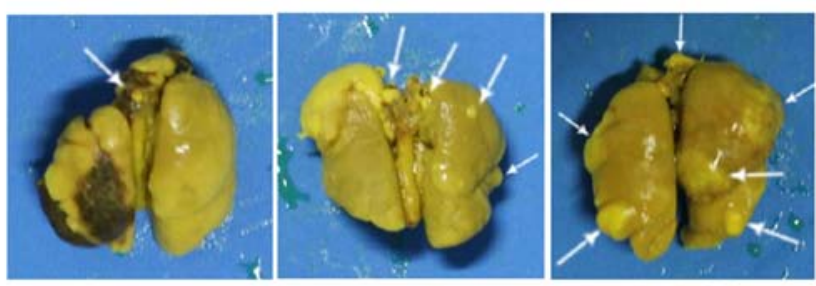

A549-NC

B
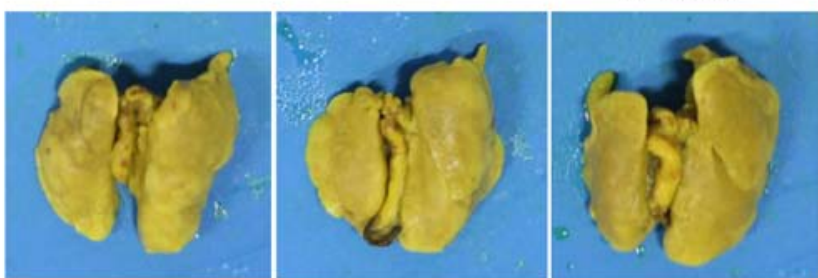

A549-GDF15

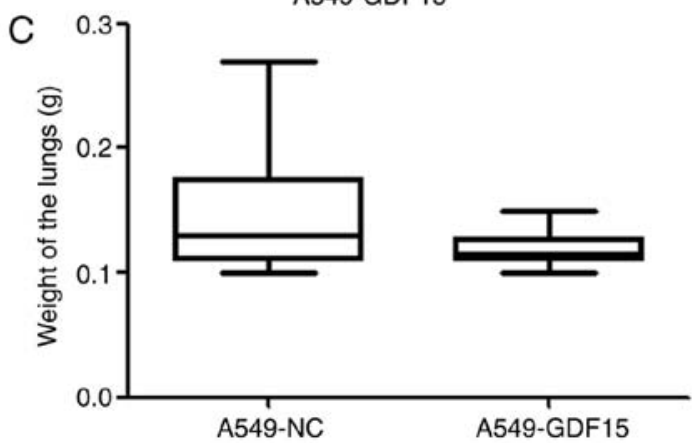

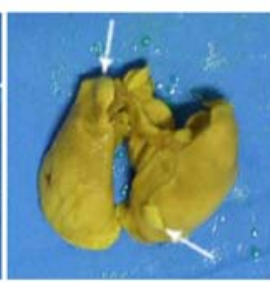
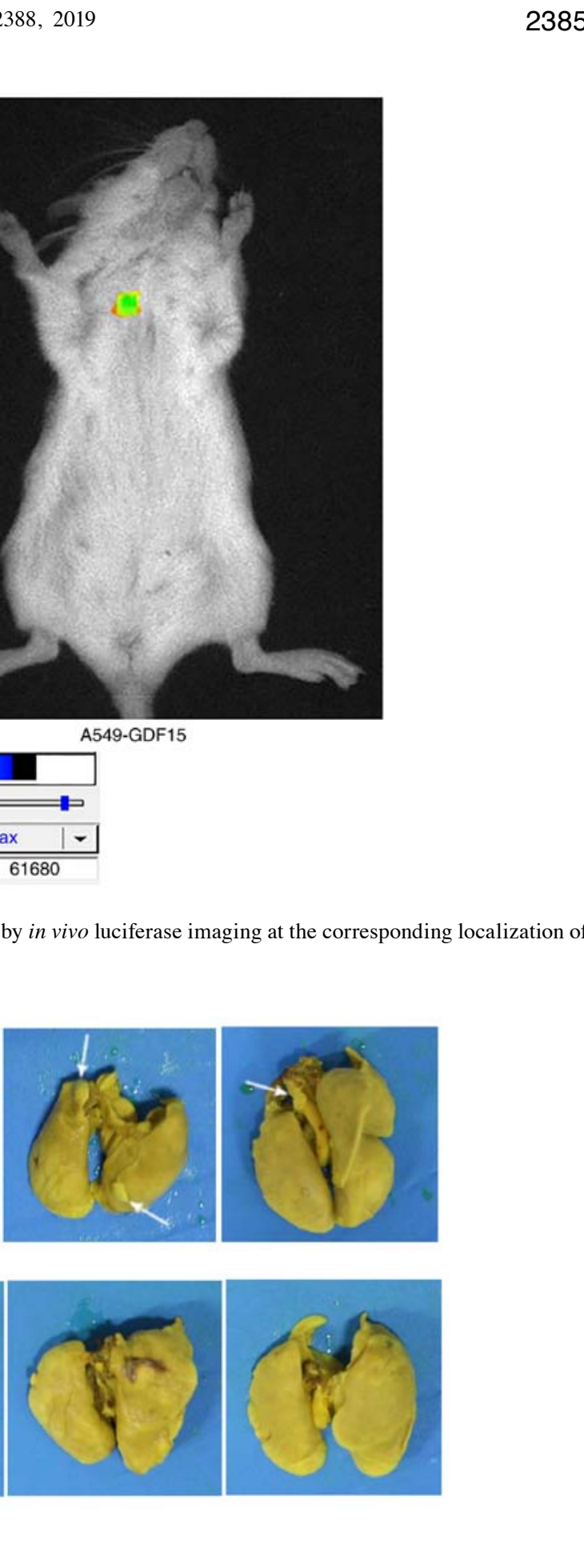


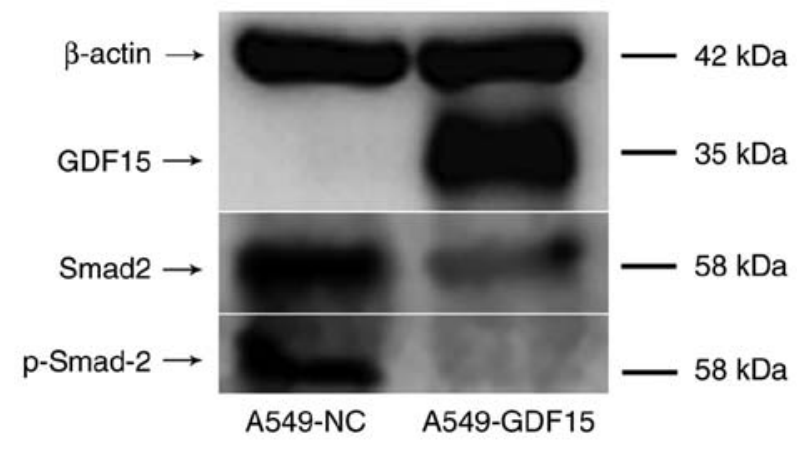

Figure 8. Differential expression of Smad2 and p-Smad2 proteins in two groups of cells.

\section{Discussion}

Growth differentiation factor 15 (GDF15), also known as macrophage inhibitory cytokine-1 (MIC1), non-steroidal anti-inflammatory drug activated gene-1 (NAG-1), placental bone morphogenetic protein (PLAB), is a member of the transforming growth factor- $\beta$ (TGF- $\beta$ ) superfamily. It is expressed in normal tissues at low levels, but is associated with hypoxemia, inflammation, acute injury and many other stress states (17), abnormal expression in a variety of tumors (18-20), cardiovascular disease (21), diabetes (22) as well as other diseases.

The role of GDF15 in tumors remains controversial. A series of studies has suggested that GDF15 is a tumor-suppressor gene, which can exert tumor suppression through the activation of tumor-suppressor pathways, such as p53 (23), glycogen

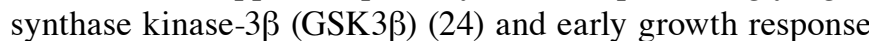
protein 1 (EGR-1) (25). Drugs that prevent tumor progression have been revealed to exert antitumor effects by upregulation of GDF15, and the most classical is non-steroidal anti-inflammatory drugs (NSAIDs), which inhibit tumor progression primarily by promoting apoptosis (26). In transgenic mouse experiments, the mice with a high-level of GDF15 had fewer and small intestinal tumors $(27,28)$, and a study based on prostate cancer mice reached similar conclusions (29). Results from studies on lung cancer were also more likely to support the notion that GDF15 inhibits the development of tumors (26). Salinomycin decreased the proliferation, migration and invasion of lung cancer cells by promoting the expression of GDF15 (30). Another study on lung cancer revealed that the tumor growth of mice treated with GDF15 was significantly inhibited, and the apoptosis of tumor cells was increased (31). These data were consistent with the present study.

However, other studies have revealed that abnormally elevated levels of GDF15 often predict more metastases, worse prognosis and drug resistance $(32,33)$. The serum levels of GDF15 were significantly higher in multiple types of malignancies and lung cancer patients with bone metastases $(\mathrm{P}<0.0001)(34)$. In addition, GDF15 promoted osteoclast differentiation while inhibiting osteoblast differentiation in vitro in multiple myeloma (35) and prostate cancer bone metastasis (36). Our conclusion appears to contradict these studies. However, as a distant relative of the TGF- $\beta$ superfamily, GDF15 is similar to other family members, as it plays a complex but not yet fully studied role in various tumors. GDF15 was revealed to be negatively correlated with the expression of hypoxia-inducible factor $\alpha$ (HIF-1 $\alpha$ ) in mice (37), whereas the activated HIF-1 $\alpha$ signaling pathway increased intracellular VEGF levels (38). It is well known that VEGF can drive tumor growth and metastasis by promoting angiogenesis. Moreover, as a secretory protein, the increased level of GDF15 expression in serum may be one of the feedback regulations of the body to resist tumor growth and bone metastasis.

It has been reported that GDF-15 is expressed at a low level in A549 cells (30), and in the present study, a recombinant GDF15 lentivirus was used to upregulate the GDF15 expression in lung adenocarcinoma A549 cells. It was revealed that GDF15 could inhibit the proliferation, migration and invasion, while promoting apoptosis in A549 cells. In addition, GDF15 significantly decreased the number and sites of lung metastases and bone metastases in vivo compared to the control group. However, the mechanism remains unclear. Numerous studies have suggested that GDF15 is related with osteoclastic differentiation, and that there may be a receptor of GDF15 in existence in osteocytes. Moreover, GDF15 was initially suggested to interact with TGF $\beta$ RII, however this has not been clearly ascertained (39). In addition, a new orphan receptor GFRAL was revealed to mediate the metabolic effects of GDF15 (40). GDF15 in lung cancer bone metastasis may be associated with the activation of its receptor. In prostate adenocarcinoma cell bone metastases, GDF15 suppressed formation of mature osteoclasts differentiated from RAW264.7 macrophages and bone-marrow precursors by M-CSF/RANKL in a dose-dependent manner, and the mechanism involved inhibition of the expression of c-Fos, carbonic anhydrase II and cathepsin $\mathrm{K}$ (a key osteoclast enzyme), as well as activity of NF- $\mathrm{\kappa B}$ by delayed degradation of I $\kappa \mathrm{B}$ carbonic and induced changes in SMAD and p38 signaling (41). GDF15 is not only expressed in the cytoplasm and ECM, but also in the nucleus. It is dynamically moved to the nucleus, exported into the cytoplasm, and further transported into the ECM, and CRM1 is a key protein involved in the exportation of GDF15 from the nucleus into the cytoplasm. Nuclear pro-GDF15 was revealed to attenuate TGF- $\beta$-mediated Smad signaling through interruption of DNA binding activity of the Smad complex upon TGF- $\beta 1$ stimulation (42). In the present study, with regard to the mechanism, the key protein Smad $2 / p-S m a d 2$ in the TGF- $\beta /$ Smad signaling pathway of A549 cells overexpressing GDF15 was significantly increased, suggesting that GDF15 may play a tumor-suppressive role by inhibiting the Smad-related pathway, however this conclusion requires more experiments to be ascertained.

Overall, our data firstly demonstrated that overexpression of GDF15 in A549 cells inhibited growth ability and bone metastasis through the TGF- $\beta /$ Smad signaling pathway. However, further study is required to investigate the details of the mechanism of GDF15 inhibition of lung cancer cell bone metastasis. As a secretory protein, the level of GDF-15 in the blood serum of both humans and mice, and also in the cultural medium (with bone metastasis or not) is very important for our research. Moreover, the receptor of GDF15 in lung cancer bone metastasis remains to be identified in a future study.

\section{Acknowledgements}

The authors are grateful for the interpretation of the X-ray images and biofluorescence imaging provided by Professor 
Qiu Xiu-Chun and her MSc student Dong An-Gang (Department of Orthopedics, Tangdu Hospital, Xi'an, China).

\section{Funding}

The present study was supported by the National Natural Science Foundation of China (nos. 81572251 and 81572814).

\section{Availability of data and materials}

All data generated or analyzed during this study are included in this published article.

\section{Authors' contributions}

LD and HLZ designed the study. LD and HLP performed all the in vitro experiments. WJC, WWS, PPC and SMW performed the animal study. WJC, WWS, PPC, SMW and LLL analyzed the data. LLL provided guidance during the study. LD and HLP were also involved in the conception of the study. All authors read and approved the manuscript and agree to be accountable for all aspects of the research in ensuring that the accuracy or integrity of any part of the work are appropriately investigated and resolved.

\section{Ethics approval and consent to participate}

All animal studies strictly abided by the Regulations on Animal Experimentation formulated by the Laboratory Animal Center of the Air Force Military Medical University (Xi'an, China) and this study was approved by the Animal Experimental Ethical Inspection Committee of this Center (no. 20171203).

\section{Patient consent for publication}

Not applicable.

\section{Competing interests}

The authors declare that they have no competing interests.

\section{References}

1. Chen W, Zheng R, Baade PD, Zhang S, Zeng H, Bray F, Jemal A, Yu XQ and He J: Cancer statistics in China 2015. CA Cancer J Clin 66: 115-132, 2016.

2. Reck M,Heigener DF, Mok T, Soria JC and Rabe KF: Management of non-small-cell lung cancer: Recent developments. Lancet 382 709-719, 2013.

3. Oliveira MB, Mello FC and Paschoal ME: The relationship between lung cancer histology and the clinicopathological characteristics of bone metastases. Lung Cancer 96: 19-24, 2016

4. Silva SC, Wilson C and Woll PJ: Bone-targeted agents in the treatment of lung cancer. Ther Adv Med Oncol 7: 219-228, 2015

5. Michaelson MD and Smith MR: Bisphosphonates for treatment and prevention of bone metastases. J Clin Oncol 23: 8219-8224, 2005.

6. Renders GA, Vermeer JA, Leung PM, Reynaert F, Prins C, Langenbach GE and Everts V: Implications of high-dosage bisphosphonate treatment on bone tissue in the jaw and knee joint. Calcif Tissue Int 95: 436-445, 2014.

7. Ma NQ, Liu LL, Min J, Wang JW, Jiang WF, Liu Y, Feng YG, Su HC, Feng YM and Zhang HL: The effect of down regulation of calcineurin Aalpha by lentiviral vector-mediated RNAi on the biological behavior of small-cell lung cancer and its bone metastasis. Clin Exp Metastasis 28: 765-778, 2011.
8. Pang H, Ma N, Shen W, Zhao Q, Wang J, Duan L, Chen W, Zhang N, Zhao Z, Liu L, et al: Effects of DKK1 overexpression on bone metastasis of SBC-3 cells. Oncol Lett 15: 6739-6744, 2018.

9. Pang H, Ma N, Jiao M, Shen W, Xin B, Wang T, Zhang F, Liu L and Zhang H: The biological effects of Dickkopf1 on small cell lung cancer cells and bone metastasis. Oncol Res 25: 35-42, 2017.

10. Ma N, Shen W, Pang H, Zhang N, Shi H, Wang J and Zhang H: The effect of RCAN1 on the biological behaviors of small cell lung cancer. Tumor Biol 39: 1010428317700405, 2017.

11. Liu Y, Zhang Y, Min J, Liu LL, Ma NQ, Feng YM, Liu D, Wang PZ, Huang DD, Zhuang Y, et al: Calcineurin promotes proliferation, migration, and invasion of small cell lung cancer. Tumor Biol 31: 199-207, 2010.

12. Ma N, Pang H, Shen W, Zhang F, Cui Z, Wang J, Wang J, Liu L and Zhang H: Downregulation of CXCR4 by SDF-KDEL in $\mathrm{SBC}-5$ cells inhibits their migration in vitro and organ metastasis in vivo. Int J Mol Med 35: 425-432, 2015.

13. Liu Y, Zhang N, Wang Y, Xu M, Liu N, Pang X, Cao J, Ma N Pang H, Liu L, et al: Zinc finger E-box binding homeobox 1 promotes invasion and bone metastasis of small cell lung cancerin vitro and in vivo. Cancer Sci 103: 1420-1428, 2012.

14. Shen W, Pang H, Xin B, Duan L, Liu L and Zhang H: Biological effects of BMP7 on small-cell lung cancer cells and its bone metastasis. Int J Oncol 53: 1354-1362, 2018.

15. Cheng GZ, Chan J, Wang Q, Zhang W, Sun CD and Wang LH: Twist transcriptionally up-regulates AKT2 in breast cancer cells leading to increased migration, invasion, and resistance to paclitaxel. Cancer Res 67: 1979-1987, 2007.

16. Livak KJ and Schmittgen TD: Analysis of relative gene expression data using real-time quantitative PCR and the $2^{-\Delta \Delta C_{\mathrm{T}}}$ method. Methods 25: 402-408, 2001.

17. Corre J, Hebraud B and Bourin P: Concise review: Growth differentiation factor 15 in pathology: A clinical role? Stem Cells Transl Med 2: 946-952, 2013.

18. Li C, Wang X, Casal I, Wang J, Li P, Zhang W, Xu E, Lai M and Zhang $\mathrm{H}$ : Growth differentiation factor 15 is a promising diagnostic and prognostic biomarker in colorectal cancer. J Cell Mol Med 20: 1420-1426, 2016.

19. Liu X, Chi X, Gong Q, Gao L, Niu Y, Chi X, Cheng M, Si Y, Wang M, Zhong J, et al: Association of serum level of growth differentiation factor 15 with liver cirrhosis and hepatocellular carcinoma. PLoS One 10: e127518, 2015.

20. Brown DA, Hance KW, Rogers CJ, Sansbury LB, Albert PS, Murphy G, Laiyemo AO, Wang Z, Cross AJ, Schatzkin A, et al: Serum macrophage inhibitory cytokine-1 (MIC-1/GDF15): A potential screening tool for the prevention of colon cancer? Cancer Epidem Biomar 21: 337-346, 2012.

21. Wollert KC, Kempf T and Wallentin L: Growth differentiation factor 15 as a biomarker in cardiovascular disease. Clin Chem 63: 140-151, 2016.

22. Berezin AE: Diabetes mellitus related biomarker: The predictive role of growth-differentiation factor-15. Diabetes Metab Syndr 10 (1 Suppl 1):): S154-S157, 2016.

23. Osada M, Park HL, Park MJ, Liu JW, Wu G, Trink B and Sidransky D: A p53-type response element in the GDF15 promoter confers high specificity for p53 activation. Biochem Biophys Res Commun 354: 913-918, 2007.

24. Lee SH, Krisanapun C and Baek SJ: NSAID-activated gene-1 as a molecular target for capsaicin-induced apoptosis through a novel molecular mechanism involving GSK3beta, C/EBPbeta and ATF3. Carcinogenesis 31: 719-728, 2010.

25. Baek SJ, Kim JS, Moore SM, Lee SH, Martinez J and Eling TE: Cyclooxygenase inhibitors induce the expression of the tumor suppressor gene EGR-1, which results in the up-regulation of NAG-1, an antitumorigenic protein. Mol Pharmacol 67: 356-364, 2005.

26. Wang X, Baek SJ and Eling TE: The diverse roles of nonsteroidal anti-inflammatory drug activated gene (NAG-1/GDF15) in cancer. Biochem Pharmacol 85: 597-606, 2013.

27. Zimmers TA, Gutierrez JC and Koniaris LG: Loss of GDF-15 abolishes Sulindac chemoprevention in the $\mathrm{Apc}^{\mathrm{Min} /+}$ mouse model of intestinal cancer. J Cancer Res Clin 136: 571-576, 2010.

28. Baek SJ, Okazaki R, Lee SH, Martinez J, Kim JS, Yamaguchi K, Mishina Y, Martin DW, Shoieb A, McEntee MF and Eling TE: Nonsteroidal anti-inflammatory drug-activated gene-1 over expression in transgenic mice suppresses intestinal neoplasia. Gastroenterology 131: 1553-1560, 2006. 
29. Husaini Y, Qiu MR, Lockwood GP, Luo XW, Shang P, Kuffner T, Tsai VW, Jiang L, Russell PJ, Brown DA and Breit SN: Macrophage inhibitory cytokine-1 (MIC-1/GDF15) slows cancer development but increases metastases in TRAMP prostate cancer prone mice. PLoS One 7: e43833, 2012.

30. Arafat K, Iratni R, Takahashi T, Parekh K, Al Dhaheri Y, Adrian TE and Attoub S: Inhibitory effects of salinomycin on cell survival, colony growth, migration, and invasion of human non-small cell lung cancer A549 and LNM35: Involvement of NAG-1. PLoS One 8: e66931, 2013.

31. Cekanova M, Lee SH, Donnell RL, Sukhthankar M, Eling TE, Fischer SM and Baek SJ: Nonsteroidal anti-inflammatory drug-activated gene-1 expression inhibits urethane-induced pulmonary tumorigenesis in transgenic mice. Cancer Prev Res 2: 450-458, 2009.

32. Wang X, Yang Z, Tian H, Li Y, Li M, Zhao W, Zhang C, Wang T, Liu J, Zhang A, et al: Circulating MIC-1/GDF15 is a complementary screening biomarker with CEA and correlates with liver metastasis and poor survival in colorectal cancer. Oncotarget 8: 24892-24901, 2017.

33. Zhang Y, Hua W, Niu LC, Li SM, Wang YM, Shang L, Zhang C, Li WN, Wang R, Chen BL, et al: Elevated growth differentiation factor 15 expression predicts poor prognosis in epithelial ovarian cancer patients. Tumor Biol 37: 8465, 2016.

34. Windrichova J, Fuchsova R, Kucera R, Topolcan O, Fiala O, Finek J and Slipkova D: MIC1/GDF15 as a bone metastatic disease biomarker. Anticancer Res 37: 1501-1506, 2017.

35. Westhrin M, Moen SH, Holien T, Mylin AK, Heickendorff L, Olsen OE, Sundan A, Turesson I, Gimsing P, Waage A, et al: Growth differentiation factor 15 (GDF15) promotes osteoclast differentiation and inhibits osteoblast differentiation and high serum GDF15 levels are associated with multiple myeloma bone disease. Haematologica 100: e511-e514, 2015.
36. Wakchoure S, Swain TM, Hentunen TA, Bauskin AR, Brown DA, Breit SN, Vuopala KS, Harris KW and Selander KS: Expression of macrophage inhibitory cytokine-1 in prostate cancer bone metastases induces osteoclast activation and weight loss. Prostate 69: 652-661, 2009.

37. Zhang Y, Jiang W, Wang L and Lingappan K: Sex-specific differences in the modulation of growth differentiation factor 15 (GDF15) by hyperoxia in vivo and in vitro: Role of Hif- $1 \alpha$. Toxicol Appl Pharmacol 332: 8-14, 2017.

38. Bertrand C, Kowalski-Chauvel A, Do C, Résa C, Najib S, Daulhac L, Wang TC, Ferrand A and Seva C: A gastrin precursor, gastrin-gly, upregulates VEGF expression in colonic epithelial cells through an HIF-1-independent mechanism. Int J Cancer 126 2847-2857, 2010

39. Johnen H, Lin S, Kuffner T, Brown DA, Tsai VW, Bauskin AR, Wu L, Pankhurst G, Jiang L, Junankar S, et al: Tumor-induced anorexia and weight loss are mediated by the TGF-beta superfamily cytokine MIC-1. Nat Med 13: 1333-1340, 2007.

40. Emmerson PJ, Wang F, Du Y, Liu Q, Pickard RT, Gonciarz MD, Coskun T, Hamang MJ, Sindelar DK, Ballman KK, et al: The metabolic effects of GDF15 are mediated by the orphan receptor GFRAL. Nat Med 23: 1215-1219, 2017.

41. Vanhara P, Lincova E, Kozubik A, Jurdic P, Soucek K and Smarda J: Growth/differentiation factor-15 inhibits differentiation into osteoclasts-a novel factor involved in control of osteoclast differentiation. Differentiation 78: 213-222, 2009.

42. Min K, Liggett JL, Silva G, Wu WW, Wang R, Shen RF, Eling TE and Baek SJ: NAG-1/GDF15 accumulates in the nucleus and modulates transcriptional regulation of the Smad pathway. Oncogene 35: 377-388, 2016. 